\title{
Prevalence of Endocrine Disorders in Childhood Brain Tumor Survivors in South Korea
}

\author{
JAESUNG HEO ${ }^{1}$, HAE SANG LEE ${ }^{2}$, JIN SON HWANG ${ }^{2}, \mathrm{O} \mathrm{KYU} \mathrm{NOH}^{1,3}$, LOGYOUNG KIM $^{4}$ and JUN EUN PARK ${ }^{2}$ \\ ${ }^{1}$ Department of Radiation Oncology, Ajou University School of Medicine, Suwon, Republic of Korea; \\ ${ }^{2}$ Department of Pediatrics, Ajou University School of Medicine, Suwon, Republic of Korea; \\ ${ }^{3}$ Office of Biostatistics, Ajou University School of Medicine, Suwon, Republic of Korea; \\ ${ }^{4}$ Health Insurance Review and Assessment Service, Seoul, Republic of Korea
}

\begin{abstract}
Background/Aim: This longitudinal study aimed to analyze the prevalence of endocrine disorders in childhood brain tumor survivors in South Korea using claims data. Patients and Methods: We identified in 1,058 patients from a nationwide cohort of patients diagnosed with brain tumors between January 1st 2009 to March 29th 2016. Multivariable logistic regression was used to evaluate associations between clinical factors and endocrine disorders. Results: After a median follow-up of 60.0 months, $393(37.1 \%)$ patients had at least 1 endocrine disorder. The commonest endocrine disorders were hypopituitarism $(17.4 \%)$ and hypothyroidism (6.1\%). Female gender (odds $\operatorname{ratio}(O R)=1.45, p=0.005)$ and age $<10$ years $(O R=1.65$, $p=0.001)$ conferred a higher risk. Patients who received radiotherapy were more likely to have endocrine disorders compared to those who did not $(O R=1.79, p<0.001)$. Conclusion: Regular assessment of endocrine function and timely interventions are necessary for childhood brain tumor survivors with a risk of endocrine disorders.
\end{abstract}

Brain tumors are the second commonest cause of cancer in children and account for $21 \%$ of all pediatric cancers (1). Advancements in treatment have allowed $74 \%$ of children diagnosed with brain tumors to become long-term survivors (2). Despite improvements in prognosis, cancer survivors continue to suffer from treatment-related side-effects that impair their quality of life (3).

This article is freely accessible online.

Correspondence to: Jun Eun Park, Department of Pediatrics, Ajou University School of Medicine, 164 Worldcup-ro, Yeongtong-gu, Suwon 16499, Republic of Korea. Tel: +82 312195168, Fax: +82 312195169, e-mail: pedpje@ajou.ac.kr

Key Words: Pediatric cancer, brain tumor survivors, endocrine disorder, Republic of Korea.
These adverse effects may be related to the tumor burden, surgical interventions, chemotherapy, or radiotherapy (4). Many of the late effects are attributable to direct damage of brain development (5), and include disorders of the endocrine system (6). Among them, childhood brain tumors located near the hypothalamic-pituitary area are particularly associated with an increased risk of hypothalamic pituitary axis (HPA) dysfunction (7).

Common endocrine complications include the growth hormone $(\mathrm{GH})$ deficiency and insufficient levels of thyrotropic and adrenocorticotropic hormones (8). In addition, the prevalence of endocrine disease among patients with childhood brain tumors is $49 \%$, and that of more than one endocrine deficiency is estimated to be $40 \%$ (9). Reports suggest that the lack of an appropriate and timely follow-up escaping diagnosis of developing endocrine disorders could result in late referrals, adversely affecting the hormone balance of these patients (10).

Reports on the number of childhood brain tumor survivors being currently treated for endocrine disorders in South Korea are scarce. In addition, recommendations for screening endocrinopathy are based on limited variables and as a result of studies in small patient populations (11). For all these reasons, we aimed to analyze large-scale nationwide data for identifying the prevalence of endocrine disorders among childhood brain tumor survivors. We also evaluated the risk factors associated with these disorders.

\section{Patients and Methods}

Patients under 18 years of age who were diagnosed with pediatric brain tumors between January 2007 and December 2016 were identified by examining data from the nationwide Korean National Health Insurance claims database. We used the Korean Classification of Disease, sixth edition, which is based on the International Classification of Diseases 10th Revision (ICD-10) (12).

Cases of brain tumors were identified by the code C71 (malignant neoplasms of brain). Those who were diagnosed with any form of cancer between 2007 and 2008 were excluded. The 
in vivo 33: $2287-2291(2019)$

Table I. The frequency of endocrine disorders in childhood CNS tumor survivors $(N=1,058)$.

\begin{tabular}{lccc}
\hline Endocrine disorders & Prevalence (\%) & Onset month, Median (range) & Onset peak duration after diagnosis (month) \\
\hline Total endocrine disorder & $393(37.1)$ & $26.3(0.1-96.7)$ & $0-2$ \\
Hypopituitarism & $184(17.4)$ & $31.8(0.5-98.6)$ & $31-32$ \\
Hypothyroidism & $65(6.1)$ & $28.0(0.2-101.8)$ & $25-26$ \\
Diabetes insipidus & $62(5.9)$ & $9.5(0.1-85.3)$ & $9-10$ \\
Precocious puberty & $49(4.6)$ & $33.4(0.2-90.4)$ & $33-34$ \\
\hline
\end{tabular}

patients who did not require oncology consultations for any type of cancer during the 2-year period (2-year washout period) since 2007 were considered to be cancer-free. The first diagnosis of an endocrine disorder was identified using claims data; the principal diagnosis was identified using ICD-10 codes based on a previous study (10). Endocrine dysfunction was identified by codes E00-E90 for endocrine disorders; screening for diseases with frequencies of at least $1 \%$ yielded 4 codes. These included hypopituitarism, hypothyroidism, precocious puberty, and diabetes insipidus (DI), coded as E230, E03, E301, and E232, respectively.

We investigated the prevalence of endocrine disorders after diagnosis and analyzed their pattern according to their time sequence. Descriptive statistics were employed to estimate the frequency of endocrine disorders during the first hospital visit based on the date of diagnosis. Differences between groups were evaluated using the Student's $t$ - and $\chi^{2}$-tests for continuous and categorical variables, respectively. Multivariate logistic regression analyses were used to estimate adjusted odds ratio (OR) for sample differences and explore demographics, which may have also influenced the development of endocrine disorders. Two-sided $p$ Values of less than 0.05 were considered statistically significant. All statistical analyses were performed using the R 3.0.2 (R Foundation for Statistical Computing, Vienna, Austria) software package.

\section{Results}

A total of 1,058 childhood brain tumor survivors who were diagnosed with cancer between 2009 and 2016 were identified from the nationwide database of South Korea. The cohort comprised $636(60.1 \%)$ males and $422(39.9 \%)$ females. The median duration of follow-up was 60.0 (range $=0.1-96.7$ ) months.

At least 1 endocrine disorder was diagnosed in 393 (37.1\%) patients. The median duration of follow-up from the diagnosis of the primary brain tumor to the diagnosis of the first endocrine disorder was 26.3 (range=0.1-96.7) months. Among the 393 survivors, 333 were diagnosed with endocrine disorders within 5 years of diagnosis of childhood brain tumors. The commonest endocrine disorders were hypopituitarism on $(n=184,17.4 \%)$, hypothyroidism $(\mathrm{n}=65,6.1 \%)$, DI $(\mathrm{n}=62,5.9 \%)$, and precocious puberty $(n=49,4.6 \%)$ (Table I).

The time to diagnosis for each endocrine disorder was identified, however for most endocrine disorders, a peak was observed at 2 months following diagnosis of pediatric brain tumors (Figure 1 and Table I). Instead, the frequency of hypopituitarism and hypothyroidism peaked at 31 and 25 months, respectively. The highest increase was noted for diabetes insipidus (Figure 1).

The frequencies of endocrine disorders according to clinical factors are summarized in Table II. There were significant differences in the status of endocrine disorders between patients aged $\geq 10$ and $<70$ years $(p=0.005)$. Radiotherapy and sex were also significant factors affecting the frequency of endocrine disorders $(p<0.001)$. Our multivariate analysis showed that female patients and young cancer survivors aged $<10$ years were at a higher risk for endocrine disorders, with respective ORs of 1.45 and 1.65 ( $p=0.005$ and $=0.001$, respectively). In addition, patients who received radiotherapy were more likely to develop endocrine disorders compared to those who did not $(\mathrm{OR}=1.79, p<0.001)$.

\section{Discussion}

Survivors of childhood brain tumors are at a significant risk of developing an endocrine dysfunction. The developmental functions regulated by thyroid hormones and $\mathrm{GH}$ are particularly important in young children $(13,14)$. In this study, we specifically evaluated the time of development of endocrine disorders following the diagnosis of brain tumors. Overall, $37.1 \%$ of childhood brain tumor survivors were diagnosed with at least 1 endocrine disorder. Previous studies have also reported the prevalence of endocrine disease among childhood brain tumor survivors to be $40 \%(9,11)$. Most endocrine disorders were identified at a median duration of 26.3 (range=0.1-96.7) months of follow-up, with the peak occurring soon after the diagnosis of the tumors. In addition, we found that: i) a relatively younger age at the time of cancer diagnosis, ii) female gender, and iii) previous history of radiation therapy were independent risk factors for endocrine disorders.

In our cohort, the commonest endocrine disorder was hypopituitarism $(n=184,17.4 \%)$. In a study by Clement et al., at least 1 dysfunction of the HPA was found in 138 (19.2\%) of 718 survivors of childhood brain tumors (10), 90 $(65 \%)$ of which were diagnosed with a GH deficiency. 
Table II. The frequency of endocrine disorders according to sex, age, and radiotherapy $(N=1,058)$.

\begin{tabular}{llcl}
\hline Variable & \multicolumn{2}{c}{ No. of patients (\%) } & \\
\cline { 2 - 3 } & $\begin{array}{c}\text { Endocrine } \\
\text { disorders }(-) \\
(\mathrm{n}=665)\end{array}$ & $\begin{array}{c}\text { Endocrine } \\
\text { disorders }(+) \\
(\mathrm{N}=393)\end{array}$ & \\
& & & \\
\hline $\begin{array}{l}\text { Gender } \\
\text { Male }\end{array}$ & $422(63.5)$ & $214(54.5)$ & \\
$\quad$ Female & $243(36.5)$ & $179(45.5)$ & \\
$\begin{array}{l}\text { Age, years } \\
<10\end{array}$ & $303(45.6)$ & $232(59.0)$ & $<0.001$ \\
$\quad 10$ & $362(54.4)$ & $161(41.0)$ & \\
$\begin{array}{l}\text { Radiotherapy } \\
\text { Yes }\end{array}$ & $303(45.6)$ & $232(59.0)$ & $<0.001$ \\
$\quad$ No & $362(54.4)$ & $161(41.0)$ & \\
\hline
\end{tabular}

Because the hypothalamus and pituitary area are sensitive to radiation, GH deficiency is the first and most frequent complication following radiotherapy for pediatric brain tumors (15). Current evidence suggests that almost $100 \%$ of children treated with radiation doses above $30 \mathrm{~Gy}$ will have blunted GH responses to the insulin tolerance test within 2 to 5 years following radiation therapy $(16,17)$.

The prevalence of hypothyroidism in our cohort was $6.1 \%$. This agreed with the prevalence of $5.8 \%$ also reported by Clement et al. (10). Hypothyroidism is common among patients with medulloblastoma who receive craniospinal irradiation, including the neck (18). In addition to pituitary disease, there is a possibility of radiation-induced thyroid carcinoma, which requires particular attention.

DI was observed in $5.9 \%$ of our study cohort, with previous studies also rarely reporting this complication following cranial radiotherapy (5). Our study also did not include craniopharyngiomas or pituitary gland tumors. However, in the study by Clement et al., DI occurred in more than $2.6 \%$ of their cohort. DI is typically diagnosed immediately after neurosurgery for low-grade gliomas or germ cell tumors (19).

Precocious puberty was diagnosed in 49 (4.6\%) of our patients. Cranial surgery or irradiation ( $>18 \mathrm{~Gy}$ ) may damage $\gamma$-aminobutyric-acid-secreting neurons, leading to premature activation of gonadotropin-releasing hormone neurons, which could herald precocious puberty $(20,21)$. In a nationwide register-based study on the normal population of Denmark, precocious puberty was found in $<0.2 \%$ female and $0.05 \%$ male children (20). In the cohort studied by Clement et al., a prevalence of up to $12.2 \%$ was observed (10). Taken together, all these different studies suggest that an active evaluation of precocious puberty, based on pubertal staging examination, is necessary.

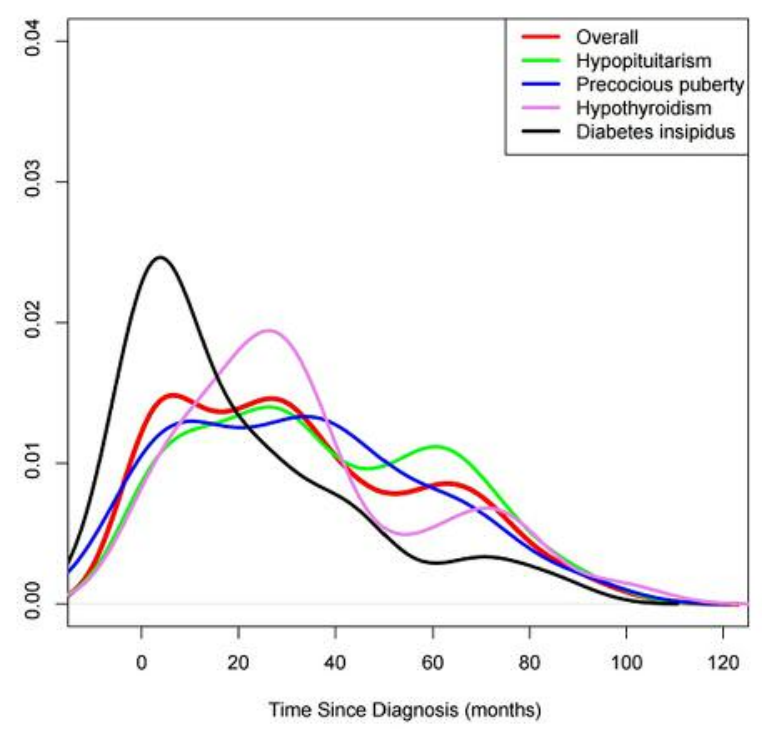

Figure 1. The frequency density of endocrine disorders in childhood brain tumor survivors (the area under density curve for each disorder is 1).

In our cohort, individual endocrine disorders had different time-dependent patterns of manifestation. The maximum time to diagnosis of an endocrine disorder was 96.7 months from the diagnosis of cancer. Among the childhood brain tumor survivors who had endocrine disorders in our study, $333(84.7 \%)$ were diagnosed with endocrine disorders during the first 5 years after the diagnosis of the tumors, with the prevalence of DI peaking at 2 months after diagnosis. In previous studies, the diagnosis of posterior pituitary deficiencies, including DI, was also made during the diagnosis and initial treatment of tumors (10). Conversely, other endocrine disorders, including pubertal disease and hypothyroidism associated with the anterior pituitary, were diagnosed within the first 5 years from the diagnosis of brain tumors (7). The occurrence of endocrine disorders in the post-treatment period may contribute to non-compliance with subsequent treatment and may impair the quality of life in these patients (22). Therefore, systemic screening and timely interventions based on the time-dependent patterns of each endocrine disorder may improve the quality of life among childhood brain tumor survivors.

The risk for endocrine disorders was higher in female patients than in male patients (10). Therefore, women require particular care. The risk was also higher in those who received radiotherapy. This may be attributed to brain-related side effects of radiation therapy (23). In addition, the risk of endocrine disorders was higher in relatively younger patients; this was probably related to brain development (24). The findings suggest that the treatment of endocrine 
disorders in these survivors requires prior knowledge of the past medical and treatment history. Personalized interventions based on individual risk factors could offer particular benefits. The Children's Oncology group guidelines have suggested screening for endocrine disorders in childhood brain tumor survivors treated with radiation therapy to doses exceeding 10 Gy (25). Moreover, recommendations of an endocrine society suggest screening for GH deficiency in children who have received hypothalamic-pituitary irradiation exceeding 10 and 12 Gy in single and multiple fractions, respectively (26).

This study has some limitations. First, we identified endocrine disorders based on claims data from the Health Insurance Review and Assessment Service, which only provided codes and demographic information. Clinical data (including cancer stage and pathologic type) were not available. Therefore, in this study, the association between endocrine diseases and tumor histologic characteristics were not analyzed. Second, the endocrine disease code was based on claims data in the clinical environment and could not be confirmed via laboratory data, including hormone levels. Third, claims data provide limited information related to treatment. The previous study confirmed a strong dosedependent relationship between radiotherapy and endocrine disorders (27), however, in our study, data on radiotherapy dose-fractionation schedules were limited. Finally, the duration of follow-up from the initial tumor diagnosis was limited. Previous studies have suggested that pituitary dysfunction occurs up to 20 years following initial diagnosis of cancer.

In conclusion, in this cohort, the prevalence of endocrine disorders among childhood brain tumor survivors was high and showed different patterns, based on the nature of disease and time sequence. In survivors of childhood brain tumors, individualized screening based on risk factors and timely interventions for endocrine disorders are necessary. Future prospective studies, including large patient samples, are needed to confirm our findings.

\section{Conflicts of Interest}

There are no conflicts of interest to disclose.

\section{Authors' Contributions}

All Authors took part in the design of the study, contributed to data collection, and participated in writing the manuscript.

\section{Acknowledgements}

The Authors would like to thank Editage (www.editage.co.kr) for English language editing. This work was supported by the Intramural Research Fund of Ajou University of Medical Center (No: M-2018-C0460-00048).

\section{References}

1 Ward E, DeSantis C, Robbins A, Kohler B and Jemal A: Childhood and adolescent cancer statistics, 2014. CA Cancer J Clin 64(2): 83-103, 2014. PMID: 24488779. DOI: 10.3322/caac. 21219

2 Armstrong GT: Long-term survivors of childhood central nervous system malignancies: The experience of the childhood cancer survivor study. Eur J Paediatr Neurol 14(4): 298-303, 2010. PMID: 20110182. DOI: 10.1016/j.ejpn.2009.12.006

3 Armstrong GT, Liu Q, Yasui Y, Huang S, Ness KK, Leisenring W, Hudson MM, Donaldson SS, King AA, Stovall M, Krull KR, Robison LL and Packer RJ: Long-term outcomes among adult survivors of childhood central nervous system malignancies in the childhood cancer survivor study. J Natl Cancer Inst 101(13): 946-958, 2009. PMID: 19535780. DOI: 10.1093/jnci/djp148

4 Knab B and Connell PP: Radiotherapy for pediatric brain tumors: When and how. Expert Rev Anticancer Ther 7(12 Suppl): S69-77, 2007. PMID: 18076312. DOI: 10.1586/ 14737140.7.12s.S69

5 Hameed R and Zacharin MR: Long-term endocrine effects of cancer treatment: Experience of the royal children's hospital, melbourne. J Paediatr Child Health 41(1-2): 36-42, 2005. PMID: 15670222. DOI: 10.1111/j.1440-1754.2005.00533.x

6 Barnes N and Chemaitilly W: Endocrinopathies in survivors of childhood neoplasia. Front Pediatr 2: 101, 2014. PMID: 25295241. DOI: 10.3389/fped 2014.00101

7 Chemaitilly W, Armstrong GT, Gajjar A and Hudson MM: Hypothalamic-pituitary axis dysfunction in survivors of childhood cns tumors: Importance of systematic follow-up and early endocrine consultation. J Clin Oncol 34(36): 4315-4319, 2016. PMID: 27998231. DOI: 10.1200/jco.2016.70.1847

8 Odagiri K, Omura M, Hata M, Aida N, Niwa T, Goto H, Ito S, Adachi M, Yoshida H, Yuki H and Inoue T: Treatment outcomes and late toxicities in patients with embryonal central nervous system tumors. Radiat Oncol 9: 201, 2014. PMID: 25209395. DOI: $10.1186 / 1748-717 \mathrm{x}-9-201$

9 Armstrong GT, Liu Q, Yasui Y, Huang S, Ness KK, Leisenring W, Hudson MM, Donaldson SS, King AA, Stovall M, Krull KR, Robison LL and Packer RJ: Long-term outcomes among adult survivors of childhood central nervous system malignancies in the childhood cancer survivor study. J Natl Cancer Inst 101(13): 946-958, 2009. PMID: 19535780. DOI: $10.1093 /$ jnci/djp148

10 Clement SC, Schouten-van Meeteren AYN, Boot AM, Claahsenvan der Grinten HL, Granzen B, Sen Han K, Janssens GO, Michiels EM, van Trotsenburg ASP, Vandertop WP, van Vuurden DG, Kremer LCM, Caron HN and van Santen HM: Prevalence and risk factors of early endocrine disorders in childhood brain tumor survivors: A nationwide, multicenter study. J Clin Oncol 34(36): 4362-4370, 2016. PMID: 27998218. DOI: 10.1200/ JCO.2016.67.5025

11 Lawson SA, Horne VE, Golekoh MC, Hornung L, Burns KC, Fouladi $M$ and Rose SR: Hypothalamic-pituitary function following childhood brain tumors: Analysis of prospective annual endocrine screening. Pediatr Blood Cancer 66(5): e27631, 2019. PMID: 30693650. DOI: 10.1002/pbc.27631

12 Kim YJ, Shin SD, Park HS, Song KJ, Cho JS, Lee SC, Kim SC, Park JO, Ahn KO and Park YM: International classification of 
diseases 10th edition-based disability adjusted life years for measuring of burden of specific injury. Clin Exp Emerg Med 3(4): 219-238, 2016. PMID: 28168229. DOI: 10.15441/ ceem. 16.126

13 Smyczynska J, Hilczer M, Stawerska R and Lewinski A: Thyroid function in children with growth hormone (gh) deficiency during the initial phase of gh replacement therapy clinical implications. Thyroid Res 3(1): 2-2, 2010. PMID: 20307267. DOI: $10.1186 / 1756-6614-3-2$

14 Deodati A and Cianfarani S: The rationale for growth hormone therapy in children with short stature. J Clin Res Pediatr Endocrinol 9(Suppl 2): 23-32, 2017. PMID: 29280742. DOI: $10.4274 /$ jcrpe. $2017 . S 003$

15 Vatner RE, Niemierko A, Misra M, Weyman EA, Goebel CP, Ebb DH, Jones RM, Huang MS, Mahajan A, Grosshans DR, Paulino AC, Stanley T, MacDonald SM, Tarbell NJ and Yock TI: Endocrine deficiency as a function of radiation dose to the hypothalamus and pituitary in pediatric and young adult patients with brain tumors. J Clin Oncol 36(28): 2854-2862, 2018. PMID: 30118397 . DOI: $10.1200 /$ jco.2018.78.1492

16 Mostoufi-Moab S and Grimberg A: Pediatric brain tumor treatment: Growth consequences and their management. Pediatr Endocrinol Rev 8(1): 6-17, 2010. PMID: 21037539.

17 Rose SR, Horne VE, Howell J, Lawson SA, Rutter MM, Trotman GE and Corathers SD: Late endocrine effects of childhood cancer. Nat Rev Endocrinol 12: 319, 2016. DOI: 10.1038/nrendo.2016.45

18 Kim MY, Yu T and Wu H-G: Dose-volumetric parameters for predicting hypothyroidism after radiotherapy for head and neck cancer. Jpn J Clin Oncol 44(4): 331-337, 2014. PMID: 24482412. DOI: $10.1093 /$ jjco/hyt235

19 Faltado AL, Macalalad-Josue AA, Li RJS, Quisumbing JPM, Yu MGY and Jimeno CA: Factors associated with postoperative diabetes insipidus after pituitary surgery. Endocrinol Metab 32(4): 426-433, 2017. PMID: 29199401. DOI: 10.3803/EnM. 2017.32.4.426

20 Juul A, Teilmann G, Scheike T, Hertel NT, Holm K, Laursen EM, Main KM and Skakkebaek NE: Pubertal development in danish children: Comparison of recent european and us data. Int J Androl 29(1): 247-255; discussion 286-290, 2006. PMID: 16466546. DOI: 10.1111/j.1365-2605.2005.00556.x

21 Stephen MD, Zage PE and Waguespack SG: Gonadotropindependent precocious puberty: Neoplastic causes and endocrine considerations. Int J Pediatr Endocrinol 2011(1): 184502184502, 2011. PMID: 21603196. DOI: 10.1155/2011/184502
22 Thomas-Teinturier C and Salenave S: Endocrine sequelae after treatment of pediatric cancer: From childhood to adulthood. Bull Cancer 102(7-8): 612-621, 2015. PMID: 25981322. DOI: 10.1016/j.bulcan.2015.03.013

23 Vatner RE, Niemierko A, Misra M, Weyman EA, Goebel CP, Ebb DH, Jones RM, Huang MS, Mahajan A, Grosshans DR, Paulino AC, Stanley T, MacDonald SM, Tarbell NJ and Yock TI: Endocrine deficiency as a function of radiation dose to the hypothalamus and pituitary in pediatric and young adult patients with brain tumors. J Clin Oncol 36(28): 2854-2862, 2018. PMID: 30118397. DOI: 10.1200/JCO.2018.78.1492

24 Cochrane AM, Cheung C, Rangan K, Freyer D, Nahata L, Dhall $\mathrm{G}$ and Finlay JL: Long-term follow-up of endocrine function among young children with newly diagnosed malignant central nervous system tumors treated with irradiation-avoiding regimens. Pediatr Blood Cancer 64(11), 2017. PMID: 28475292. DOI: $10.1002 / \mathrm{pbc} .26616$

25 Children's Oncology Group: Long-term follow-up guidelines for survivors of childhood, adolescent and young adult cancers. 2014. Available from: http://www.survivorshipguidelines.org/ pdf/COG\%20LTFU\%20Guidelines\%20Archive/Version\%204.0/ COG_LTFU_Guidelines_v4\%20(secured).pdf (last accessed on August 2, 2019)

26 Sklar CA, Antal Z, Chemaitilly W, Cohen LE, Follin C, Meacham LR and Murad MH: Hypothalamic-pituitary and growth disorders in survivors of childhood cancer: An endocrine society clinical practice guideline. J Clin Endocrinol Metab 103(8): 2761-2784, 2018. PMID: 29982476. DOI: 10.1210/ jc. $2018-01175$

27 Gleeson HK and Shalet SM: The impact of cancer therapy on the endocrine system in survivors of childhood brain tumours. Endocr Relat Cancer 11(4): 589-602, 2004. PMID: 15613441. DOI: $10.1677 /$ erc.1.00779
Received July 17, 2019

Revised August 1, 2019

Accepted August 2, 2019 